\title{
Designing learning environments for cultural inclusivity: A case study of indigenous online learning at tertiary level
}

\author{
Catherine McLoughlin \\ The University of New England \\ Ron Oliver \\ Edith Cowan University
}

Flexible delivery of educational resources must take account of cultural variables and recognise the specific learning needs, preferences and styles of learners. In designing instruction, there may be a tension between the need to ensure access for a diverse student population, while at the same time taking into account the need for localisation to accommodate learners' particular cultures, cognitive styles and preferences. Considering the micro and macro cultural levels of instructional design is therefore essential if appropriate learning environments are to be created. The acceptance, use and impact of WWW sites is affected by the cultural backgrounds, values, needs and preferences of learners.

One of the limitations in current instructional design models is that they do not fully contextualise the learning experience, and are themselves the product of particular cultures. The design of Web based instruction is not culturally neutral, but instead is based on the particular epistemologies, learning theories and goal orientations of the designers themselves. Recently, theorists have argued for a cultural dimension in the design process and the need to provide culturally sensitive learning environments.

In this paper, we trace the design processes involved in the development of an online learning environment for indigenous Australian learners preparing to enter university, and account for the cultural issues that impacted on creation of learning tasks and styles of communication. The paper argues for cultural localisation, which means incorporating the local values, styles of learning and cognitive preferences of the target population. It also means going beyond surface level design considerations, to achieve culturally inclusive constructivist learning environments. Examples of tasks, activities and forms of online interaction are provided in the context of a bi-cultural model of learning that recognises diversity and different learning needs. It is recommended that when creating WWW based course support sites for cultural inclusivity, systematic attention must be given to 
particular design guidelines, which include responsiveness to learner needs, community based learning and cultural contextualisation of learning activities.

\section{Cultural dimensions in the design process: Recognising diversity}

Culture pervades learning, and in designing instructional environments there needs to be serious debate about issues concerning the social and cultural dimensions of task design, communication channels and structuring of information if the needs of culturally diverse learners are to be met. Educational computing, or the use of technology to mediate learning, is imbued with cultural values and assumptions. Research has shown that computer based collaborative work can transform classroom cultures, the roles of teachers and students and the expectations of learners (Damarin, 1998; De Voogd, 1998).

Reeves \& Reeves (1997) emphasise that greater challenges may arise when the core pedagogical values in one culture are culturally inappropriate in another: for example the expectation that students will question knowledge or the teacher is a not a universally accepted form of interaction. Reeves concludes that not enough is known about the complexities of cultural inclusivity for cognitive design of learning resources and that further research is needed. Collis et al (1996) similarly conclude that there is little extant research on instructional design for cross cultural Web site development.

\section{Cultural aspects of WWW design}

As learning is a cultural activity, the design of Web sites is also infused with cultural meaning and with cultural nuances and identity issues, as the instructional designers and developers bring their own viewpoints and perspectives into the design process.

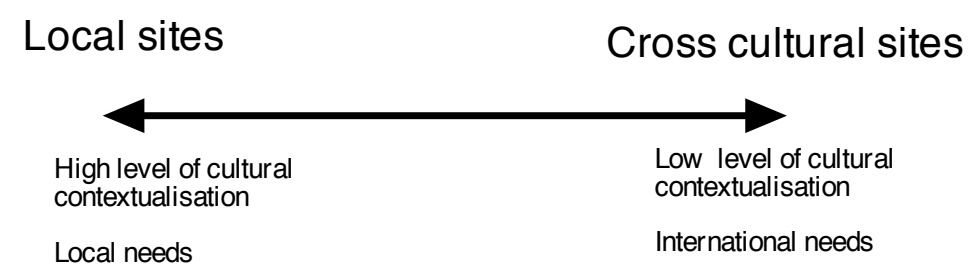

Figure 1: Categories of Web sites

Collis \& Remmers (1997) have defined two categories of sites that have cross cultural implications: 
Category 1 Sites that are 'local' in the sense that they are made in one context and culture, but visited by other cultures

Category 2 Sites that are 'international' or designed specifically for cross cultural participation. (See Figure 1.)

Category $1 \mathrm{Web}$ sites, for example, are made for a local context and culture and may not be culturally portable, as they are highly contextualised and embedded in the nuances and interaction styles of a particular culture and serve the needs of a particular audience. Category 2 sites are those which strive to reach a cross cultural population, and serve the needs of an international audience. If cross cultural Web sites are to be developed for international use, there needs to be consideration of a range of instructional design issues so that cross cultural participation and communication is made possible for all participants. However, cultural variations in interpreting and communicating information are influenced by pedagogical and instructional design decisions, and the cultural dimensions of learning must be constantly problematised and not marginalised (Wild \& Henderson, 1997).

It has been argued that one of the essential foundations of student centered learning environments is cultural inclusivity with a focus on enabling learners to access learning resources in a manner that is congruent with their values, beliefs and styles of learning (Chen, Mashadi et al., 1998). This perspective would support designing sites for local needs with high levels of cultural contextualisation. In other words, it may be assumed that highly contextualised and culturally specific learning environments are likely to meet the needs of the learners for whom they are intended, if appropriate design princples are applied. Technologies are not value free however. Joo (1999) suggests that the use of the Internet affects learner-teacher relations within the micro-culture of the classroom and macro-culture of the larger political arena, and promotes an independent, exploratory view of learning that may be alien to students who have experienced asymmetrical, teacher centred pedagogies. Distributed communities of inquiry are flourishing and are quite foreign to the centralized and hierarchical systems for knowledge distribution in many countries (Lauzon, 1999). In summary, we can conclude that the design of WWW instructional environments is imbued with cultural meanings and can influence modes of communication, styles of learning and participation at both micro and macro levels. 


\section{Culture, constructivist learning and situated cognition}

Increasingly, technologies are being described as 'cognitive tools', which transform, augment and support cognitive engagement among peers, school age children and adult learners (Jonassen et al, 1999). Cole (1985) describes technology as a 'cultural amplifier' signifying that it transforms the nature of human productivity it can also quantitatively change the processes of cognition and amplify the cultural dimensions of communication, task analysis and problem solving. Similarly, Brown, Collins \& Duguid (1989) analyse learning as a situated achievement, incorporating authentic cultural activity in a range of settings.

Within the last ten years, the culture of teaching has also undergone transformation: teachers have been urged to encourage more collaborative structures for learning, which have been shown to be effective in terms of learning outcomes (Crook, 1995; Webb, Troper et al, 1995). These pedagogies spring from a common source, constructivist learning theory (Duffy \& Cunningham, 1996). Constructivism is characterised by a set of principles relating to how knowledge is created and how individuals develop understanding. Socio-cultural theory, originating with the writings of Vygotsky (1978) emphasises that learning is a form of enculturation, in which the individual is socialised through gradual participation in tasks, scaffolded or assisted by adults until full competence is attained. One interpretation of constructivism is situated cognition, based on the work of Lave (1988) who maintains that learning is best achieved when learning tasks are encountered, practiced and applied in real world contexts. Situated cognition can be summarised as follows:

- Learning is situated and contextualised in action and everyday situations;

- Knowledge is acquired through active participation;

- Learning is a process of social action and engagement involving ways of thinking, doing and communicating;

- Learning can be assisted by experts or supportive others and through apprenticeship;

- Learning is a form of participation in social environments.

The community of inquiry approach (Lipman, 1991) is based on the same principles of cognitive apprenticeship, common goals, shared inquiry and peer learning and offers a robust theoretical basis for the design of culturally specific environments. With its emphasis on collaboration, shared experience and participation, the community of inquiry model has 
been used as an epistemological framework to address the needs of culturally diverse learners (McLoughlin, 1999; McLoughlin \& Oliver, 1999). In addition to adopting an appropriate pedagogical foundation for cultural inclusivity, issues of cultural inclusivity in instructional design must also be considered.

\section{Is cultural pluralism possible in instructional design?}

In order to design a culturally appropriate online unit of instruction, instructional designers need to follow design principles and instructional methods that best attain the desired outcomes. Instead of applying a set of prescriptive theories, instructional design needs to be sufficiently flexible and to ensure that learning activities and tasks are designed to take learners' needs and perspectives into account. According to Scheel \& Branch (1993: 8) 'instruction which acknowledges and incorporates cultural backgrounds regardless of subject matter domain, may be called culturally pluralistic instruction'.

There are many current instructional design models and paradigms, each of which can be interpreted as culturally and socially determined (Branch, 1997). Instructional design models include cognitive, social and pedagogical issues, but may not acknowledge the need for cultural contextuality. Reeves \& Reeves (1997, p. 63) for instance, outline a dozen pedagogical dimensions that can be used to design interactive multimedia tools and learning environments. Among these dimensions is cultural sensitivity which is explained as follows: 'Web based instruction should accommodate diverse ethnic and cultural backgrounds among the learners expected to use it'. Henderson (1996: 86) has argued that . 'Instructional design cannot and does not, exist outside of a consideration of culture', and that it impinges on notions of cultural identity and cannot be culturally neutral. How then, can the dimensions of cultural contextuality inform instructional design?

An important part of Henderson's (1996, 1994) work has been the identification of several design paradigms, each of which reflects particular world views, and consists of values, pedagogies, inclusions, and exclusions that results from the designers own societal context. As instructional designers are instrumental in creating and developing interactive multimedia, courseware and learning environments, they can also influence material and symbolic culture. Among the instructional design paradigms identified by Henderson there are three identifiable approaches, all of which are limited with respect to cultural dimensions of learning and pedagogy. (See Table 1). These can be summarised as follows: 
- the inclusive or perspectives approach which imports the social, cultural and historical perspectives of minority groups, but does not challenge the dominant culture and is therefore cosmetic;

- the inverted curriculum approach which attempts to design an instructional component from the minority perspective but fails to provide the learners with educationally valid experiences as it does not admit them into the mainstream culture;

- the culturally unidimensional approach which excludes or denies cultural diversity and assumes that educational experiences are the same for minority students as they are for others.

Table 1: Existing instructional design (ID) paradigms and their limitations

\begin{tabular}{|c|c|c|}
\hline ID Paradigm & Definition & Limitations \\
\hline $\begin{array}{l}\text { Inclusive or } \\
\text { perspectives }\end{array}$ & $\begin{array}{l}\text { Acknowledges } \\
\text { multicultural realities, } \\
\text { driven by equity and } \\
\text { social justice }\end{array}$ & $\begin{array}{ll}\text { - } & \text { soft multiculturalism } \\
\text { - } & \text { inclusion of the exotic } \\
\text { - } & \text { tokenism }\end{array}$ \\
\hline $\begin{array}{l}\text { Inverted } \\
\text { curriculum } \\
\text { approach }\end{array}$ & 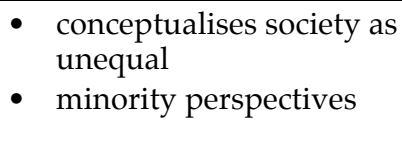 & $\begin{array}{l}\text { - does not cater for cognitive } \\
\text { needs } \\
\text { - does not support equity in } \\
\text { learning outcomes }\end{array}$ \\
\hline $\begin{array}{l}\text { Culturally } \\
\text { unidimensional }\end{array}$ & $\begin{array}{ll}\text { - } & \text { cultural minorities are } \\
\text { invisible } \\
\text { - } \\
\text { culture is presented as } \\
\text { homogenous }\end{array}$ & $\begin{array}{l}\text { - dominant cultures only are } \\
\text { acknowledged } \\
\text { - } \\
\text { culture is represented as } \\
\text { peripheral }\end{array}$ \\
\hline
\end{tabular}

Henderson proposes a further instructional design model, which is a multiple cultural model of instructional design. This is characterised by an approach which endorses multiple cultural realities or zones of development (Vygotsky, 1978). Essentially, this approach is a form of 'eclectic paradigm' which entails designing learning resources that allow variability and flexibility while enabling students to learn through interaction with materials that:

- reflect the multicultural realities of society;

- include multiple cultural ways of learning and teaching;

- promote equity of learning outcomes. 
Application of the multiple cultural model requires a global and inclusive perspective, sensitivity to cultural difference and an appreciation of the numerous ways in which culture influences learning. Instructional designers need to consider the philosophical and pedagogical underpinning of goals, objectives, content and instructional activities, and incorporate not one, but multiple pedagogies according to learner needs. The design should also be validated by a member of the group or groups to whom the learning materials are addressed, and materials need to be tested with the target groups during the development phase to ensure authenticity.

The adoption of the multiple cultural model requires the design team to investigate the pedagogical dimensions of the cultures they are providing resources for, and to be aware of the multiple ways in which each culture could interpret instruction. Some questions that would require answers are:

- What kind of learning environment is most familiar to the students?

- How does the cultural background of these students influence their conceptions of learning?

- How do students conceive the role of the teacher?

- What kind of relationship do students want with an online tutor?

- What kinds of assessment tasks will support learning and cultural inclusivity?

- What rewards and forms of feedback will be most motivating for these students?

- Is the locus of control congruent with these students' own sense of personal control?

- What cognitive styles characterise the target group?

In the context of designing an online unit for indigenous Australian learners, a pragmatic approach to culturally appropriate design is proposed. This entails drawing on current knowledge of pedagogical, cultural and epistemological factors that influence learning and communication, and then generating guidelines that minimize deficit views of cultural difference, while promoting contructivist, contextualised, culturally responsive learning. The following design principles emerged from empirical work conducted in the process of designing tertiary level units of study for indigenous learners seeking entry to university. (See Table 2 for a summary of design guidelines). 


\section{Ten design principles for culturally inclusive instructional design}

1. Adopt an epistemology that is consistent with, and supportive of constructivist learning and multiple perspectives.

For indigenous Australian students, becoming bicultural is part of their adaptation to learning in tertiary study, and fundamental to academic success. Many approaches to the education of indigenous students have been labeled reductionist or based on a deficit model, as they implicitly espouse the view that Aboriginal students enter universities without the requisite skills and have to be remediated into mainstream tertiary settings. This deficit view is negative and destructive and denies learner input. The adoption of the 'community of practice model' for online delivery enables learners to have access to community knowledge, support structures and shared interests (McLoughlin, 1999). This form of emancipatory pedagogy ensures recognition of students' capacity to construct their own knowledge, bring prior experience and culturally preferred ways of knowing to learning tasks and develop a sense of ownership and pride in their own knowledge.

\section{Design authentic learning activities.}

In adult indigenous education, instructional design of educational programs must incorporate the skills and values of the community, its cultural traditions and its values and issues in order to create a unified and authentic learning environment. Subject matter that is relevant to these communities must be taught (Hobson, 1997). In Australia and North America, research conducted with indigenous adults shows that purely cognitive based approaches have had limited success, while interactive, dialogic approaches have been found to equip indigenous students with the analytic and verbal skills they need to succeed in the contemporary world (Ryan, 1992; McCarthy et al, 1991).

\section{Create flexible tasks and tools for knowledge sharing.}

One of the basic principles of instructional design is that indigenous learners should be able to share what they have constructed with others. This reinforces the social, collaborative focus of learning and creates and online community. Collaborative task design that enables groups to combine expertise and distribute control for parts of the task affirms learner control. Knowledge sharing can be fostered by designing bulletin boards for students to discuss assignments, offer peer support and feedback. 


\section{Ensure different forms of support, within and outside the community.}

One of the principles of a 'community of practice' is that there is scaffolding for novices until they develop skill and competence. In an online community, similar structures can be provided to learners through Web based tools. The tutors can engage with students in dialogue though discussion forums, and can provide examples of communication protocols and learning processes that are required in tasks. Models of ideas from other tertiary graduates are additional resources that students can access, and bulletin boards give students an opportunity to engage in guided reflective discussion with tutors and peers. Figure 1 is an illustration of the help desk feature which provides multiple forms of support for indigenous online learners, including Telephone assistance, Online mentor and Frequently asked questions.

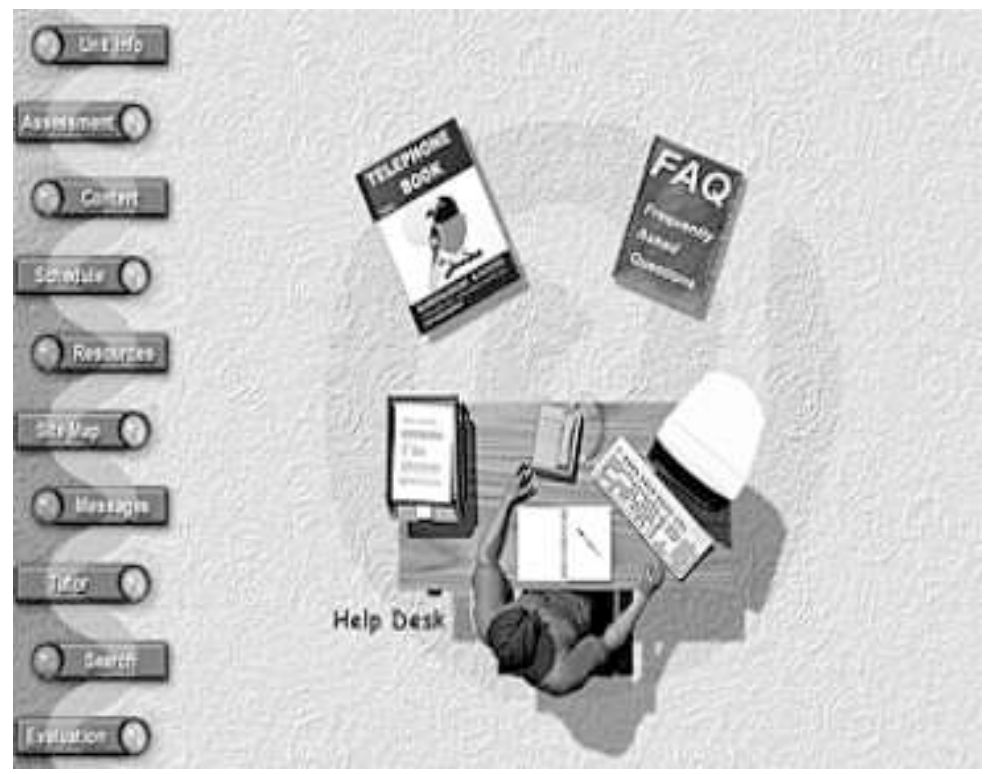

Figure 1: The online help desk offering multiple forms of scaffolding

5. Establish flexible and responsive student roles and responsibilities.

From the outset, awareness of student needs must inform the design process. For most students, initiation into an online community is often a new experience and therefore technology related skills have to be learnt. Clear communication of learning outcomes can be established 
through the design of the Web site, with navigation tools to allow multi-layered exploration of unit requirements, assessment tasks and learning activities. Learners should not expected to have advanced computing skills, but development of information literacy skills need to be integral to the learning outcomes.

6. Provide communication tools and social interaction for learners to coconstruct knowledge.

Learners should be able to access multiple channels of communication with tutors and with other learners. Through the use of chat rooms and bulletin boards, learners can share ideas, discuss topics and participate in a virtual classroom. Social interaction can be fostered through an informal, virtual meeting place or 'Yarning Place' where new topics can be raised and personal interests explored. Figure 2 shows a 'Yarning place' bulletin board, which offers a range of discussion tools, social interaction spaces and feedback channels.

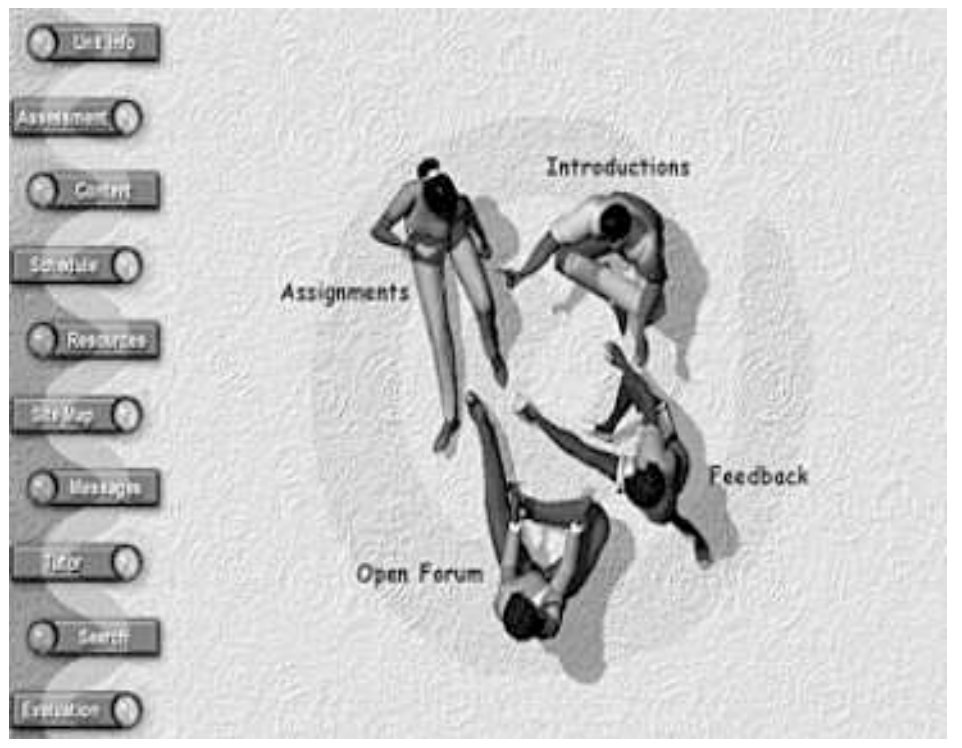

Figure 2: The Yarning place bulletin board, including negotiated interaction and feedback forum, and forum for social interaction.

7. Create tasks for self direction, ownership and collaboration.

For indigenous community members a sense of place is critical to identity and belonging. In the academic unit of study described here, 
students can create their own sense of progress and decide on a learning path that will lead them to successful completion of the unit. Various tasks and choices are presented, and a reflective space (an online journal) is provided to enable students to consider decisions taken and to alter their course of action if so desired. Shared workspaces are also provided for distributed groups of students working on projects. In addition, students are encouraged to explore the wider learning space of the Web by searching for URL's and resources to augment the ones provided. In this way, affirmation of learner contribution to the online experience is realised.

8. Ensure flexible tutoring and mentoring roles that are responsive to learner needs.

If students are studying online for the first time, the need for support, conversation and direction may be great at the initial stages of the course. Roles of tutors need to be interchangeable and modifiable in the light of student feedback. In Web based environments, flexibility and support can be built in by ensuring that tutors have an online presence that is visible, with help features and discussion forums providing learners with rapid feedback and scaffolding.

9. Create access to varied resources to ensure multiple perspectives.

This can be achieved by moving away from instructivist approaches where all texts are prescribed by the teacher to constructive approaches where learners actively add to the resources by posting new URL's, suggesting additional resources of interest and discussing alternatives through the bulletin boards. For indigenous learners the creation and inclusion of the indigenous perspectives is an important dimension and a means of recognising and integrating cultural knowledge.

\section{Provide flexibility in learning goals, outcomes and modes of assessment.}

The WWW can support flexibility in many forms, and learners should have control over their own learning goals, the topics they choose to research and the pace and sequence in which they access the resources. For indigenous learners studying online, flexibility in assessment is essential, as many are mature age learners with diverse life experiences and close community ties that need to be maintained while studying at tertiary level. By offering choice and structure learners can develop self knowledge of their own learning needs and levels of performance. 
Table 2 provides a summary of the design guidelines and features for planning an online unit for indigenous Australian learners commencing tertiary study.

Table 2: Design guidelines for flexible, culturally responsive Web design

\begin{tabular}{|l|l|}
\hline Cognitive/cultural issue & \multicolumn{1}{|c|}{ Instructional design consideration } \\
\hline $\begin{array}{l}\text { Awareness of learner needs } \\
\text { and preferences }\end{array}$ & $\begin{array}{l}\text { Instruction and learning tasks must support } \\
\text { differences in learning style and } \\
\text { communication. }\end{array}$ \\
\hline $\begin{array}{l}\text { Communication and social } \\
\text { interaction }\end{array}$ & $\begin{array}{l}\text { Multiple channels and forums for } \\
\text { communication between learners and tutors } \\
\text { should be provided. }\end{array}$ \\
\hline Authentic task design & $\begin{array}{l}\text { Learning activities build on diversity and } \\
\text { provide bridges to the students' culture and } \\
\text { community. }\end{array}$ \\
\hline $\begin{array}{l}\text { Multiple perspectives and } \\
\text { access to resources }\end{array}$ & $\begin{array}{l}\text { Enable learners to create resources and to add } \\
\text { culturally relevant sources of information. } \\
\text { Emphasise learner input. }\end{array}$ \\
\hline Scaffolding and support & $\begin{array}{l}\text { Students need scaffolding or support } \\
\text { structures to ensure that they develop skills } \\
\text { and confidence. Include peer scaffolding in } \\
\text { task design. }\end{array}$ \\
\hline $\begin{array}{l}\text { Flexibility in goals, modes } \\
\text { of assessment and learning } \\
\text { outcomes }\end{array}$ & $\begin{array}{l}\text { Ensure flexibility and inclusivity by offering } \\
\text { choice, multiple modes of delivery and } \\
\text { assessment. Students should be able to choose } \\
\text { their own pathways through the content and } \\
\text { negotiate tasks for assessment. }\end{array}$ \\
\hline $\begin{array}{l}\text { Collaboration and co- } \\
\text { construction } \\
\text { requirements }\end{array}$ & $\begin{array}{l}\text { Create multiple roles for online tutors and } \\
\text { mentors at various stages of the course to } \\
\text { ensure provision of feedback and support. }\end{array}$ \\
\hline integration of skills & $\begin{array}{l}\text { Create motivating tasks where learners can } \\
\text { share ideas and work on projects, drawing on } \\
\text { cultural resources. }\end{array}$ \\
\hline $\begin{array}{l}\text { Plan for maximum clarity and ease of use, } \\
\text { while designing for choice. Avoid } \\
\text { assumptions about cultural stereotypes and } \\
\text { expectations. }\end{array}$ \\
\hline $\begin{array}{l}\text { Plan activities so that technology use and } \\
\text { information access and become part of } \\
\text { students' repertoire of study skills and } \\
\text { lifelong learning strategies. }\end{array}$ \\
\hline
\end{tabular}




\section{Conclusions and implications for practice}

The rationale for considering culture as a design dimension for effective WWW instruction is straightforward: it enables learners to develop a cognitive anchor for new knowledge and enables them to relate and integrate new concepts within a coherent perspective that recognises and values their cultural heritage. It is recommended that instructional designers begin the process of culturally inclusive design by adopting the epistemology and pedagogy of social, constructivist learning. By recognising that learning is culturally and socially contextualised, the design process becomes grounded and located within the communities and individuals for whom the learning materials are intended. Tasks and environment design need to be imbued with the particular culture, values and expectations of the target group. By designing from a culturally informed, constructivist theory such as situated cognition or cognitive apprenticeship, instructional designers can plan activities where learning is a process of participation, communication and co-construction of knowledge (Collins, Brown \& Newman; 1989; Branch, 1997).

Culturally inclusive Web based environments should provide learning activities, supportive contexts, and learning processes that allow for inclusivity and flexibility, while offering learners a scaffolded, structured learning environment. To achieve this balance, instructional designers need to move beyond the narrowly prescriptive boundaries of current instructional design models. It is proposed that a multiple cultural model of design that caters for diversity, flexibility and cultural inclusivity in the design process affirms the social and cultural dimensions of constructed meaning.

\section{References}

Branch, R. M. (1997). Educational technology frameworks that facilitate culturally pluralistic instruction. Educational Technology, 37(2), 38-41.

Brown, J. S., Collins, A., \& Duguid, P. (1989). Situated cognition and the culture of learning. Educational Researcher, 18, 32-42.

Chen, A., Mashadi, A., Ang, D., \& Harkrider, N. (1999). Cultural issues in the design of technology enhanced learning systems. British Journal of Educational Technology, 30(3), 231-245.

Cole, M. (1985). The zone of proximal development: Where culture and cognition create each other. In J. V. Wertsch (Ed.), Culture and cognition: Vygotskyan perspectives (pp. 146-161). Cambridge: Cambridge University Press.

Collis, B., Parisi, D., \& Ligorio, M. B. (1996). Adaptation of courses for transEuropean tele-learning. Journal of Computer Assisted Learning, 12, 47-62. 
Collis, B., \& Remmers, E. (1997). The World Wide Web in education: Issues related to cross cultural communication and interaction. In B. Khan (Eds.), Web based instruction (pp. 85-92). Englewood Cliffs, New Jersey: Educational Technology Publications.

Crook, C. (1995). On resourcing a concern for collaboration within peer interactions. Cognition and Instruction, 13(4), 541-547.

Damarin, S. K. (1998). Technology and multicultural education: The question of convergence. Theory into Practice, 37(1), 11-19.

DeVoogd, G. L. (1998). Computer use and power sharing: Multicultural students' styles of participation and knowledge. Computers and Education, 31, 351-364.

Duffy, T. M., \& Cunningham, D. J. (1996). Constructivism: Implications for the design and delivery of instruction. In D. H. Jonasssen (Ed.), Handbook of research for educational communications and technology (pp. 170-198). London: Prentice Hall International.

Henderson, L. (1994). Reeve's pedagogic model of interactive learning systems and cultural contextuality. In C. McBeath and R. Atkinson (Eds.), Proceedings of the Second International Interactive Multimedia Symposium, 189-203. Perth, Western Australia, 23-28 January. Promaco Conventions.

http:/ / cleo.murdoch.edu.au/gen/aset/confs/iims/94/hj/henderson.html

Henderson, L. (1996). Instructional design of interactive multimedia. Educational Technology Research and Development, 44(4), 85-104.

Hobson, J. (1997). Strategies for building an indigenous Australian cybercommunity Paper presented at the 1997 Fulbright Symposium: Indigenous Cultures in an interconnected world.

Jonasssen, D. H., Peck, K. L., \& Wilson, B. G. (1999). Learning with technology: A constructivist perspective. Upper Saddle River, New Jersey: Merrill.

Joo, J.-E. (1999). Cultural issues of the Internet in classrooms. British Journal of Educational Technology, 30(3), 245-250.

Lave, J. (1988). Cognition in practice: Mind, mathematics and culture in everyday life. Cambridge: Cambridge University Press.

Lipman, M. (1991). Thinking in education. Cambridge: Cambridge University Press.

McCarthy, T. L., Lynch, R. H., Wallace, S., \& A. Benally (1991). Classroom inquiry and Navajo learning styles: A call for reassessment. Anthropology and Education Quarterly, 22(1), 42-59.

McLoughlin, C., \& Oliver, R. (1999). Instructional design for cultural difference: A case study of indigenous online learning in a tertiary context. In J. Winn (Ed.), ASCILITE '99 -Responding to Diversity: Proceedings of the 16th annual conference of the Australasian Society for Computers in Learning in Tertiary Education (pp. 229238). Brisbane: Queensland University of Technology. 
McLoughlin, C. (1999). Culturally responsive technology use: Developing an online community of learners. British Journal of Educational Technology, 30(3), 231-245.

Reeves, T. \& Reeves, P. (1997). Effective dimensions of interactive learning on the World Wide Web. In B. Khan (Eds.), Web based instruction (pp. 59-66).

Englewood Cliffs, New Jersey: Educational Technology Publications.

Ryan, J. (1992). Aboriginal learning styles: a critical review. Language, culture and curriculum, 5(3), 161-183.

Scheel, N. P., \& Branch, R. C. (1993). The role of conversation in the systematic design of instruction. Educational Technology, 33(8), 7-18.

Vygotsky, L. (1978). Mind in society: The development of higher psychological processes. Cambridge MA: Harvard University Press. (Original material published in 1930, 1933 and 1935).

Webb, N., Troper, J. D., \& Fall, R. (1995). Constructive activity and learning in collaborative small groups. Journal of Educational Psychology, 87(3), 406-423.

Wild, M., \& Henderson, L. (1997). Contextualising learning in the World Wide Web: accounting for the impact of culture. Education and Information Technologies, 2, 179-192.

Dr Catherine McLoughlin is Senior Lecturer in Higher Education in the Teaching and Learning Centre, The University of New England, Armidale, NSW 2351, Australia.

Tel: +61267732670 Fax: +61267733269

Email: mcloughlin@metz.une.edu.au

Dr Ron Oliver is Associate Professor in the School of Communications and Multimedia, Edith Cowan University, 2 Bradford St, Mt Lawley WA 6050, Australia.

Tel: +61 893706372 Fax: +61 893706668

Email: r.oliver@cowan.edu.au

http: / / elrond.scam.ecu.edu.au/oliver/ 